\title{
THE
}

\section{Efficient Detection of Polycyclic Aromatic Hydrocarbons and Polychlorinated Biphenyls via Three-Component Energy Transfer}

\author{
Nicole Serio \\ University of Rhode Island \\ Kayla Miller \\ University of Rhode Island \\ Mindy Levine \\ University of Rhode Island, m_levine@uri.edu
}

Follow this and additional works at: https://digitalcommons.uri.edu/chm_facpubs

The University of Rhode Island Faculty have made this article openly available.

Please let us know how Open Access to this research benefits you.

This is a pre-publication author manuscript of the final, published article.

Terms of Use

This article is made available under the terms and conditions applicable towards Open Access

Policy Articles, as set forth in our Terms of Use.

\section{Citation/Publisher Attribution}

Serio, N., Miller, K., \& Levine, M. (2013). Efficient Detection of Polycyclic Aromatic Hydrocarbons and Polychlorinated Biphenyls via Three-Component Energy Transfer. Chem. Commun., 49, 4821-4823. doi: 10.1039/C3CC40534F

Available at: http://dx.doi.org/10.1039/C3CC40534F 


\title{
Efficient detection of polycyclic aromatic hydrocarbons and polychlorinated biphenyls via three-component energy transfer
}

\author{
Nicole Serio, ${ }^{a}$ Kayla Miller, ${ }^{a}$ and Mindy Levine ${ }^{a_{*}}$ \\ Received (in $X X X, X X X)$ Xth $X X X X X X X X X 20 X X$, Accepted Xth $X X X X X X X X X 20 X X$ \\ ${ }_{5}$ DOI: 10.1039/b000000x
}

Reported herein is the detection of highly toxic polycyclic aromatic hydrocarbons (PAHs) and polychlorinated biphenyls (PCBs) via proximity-induced non-covalent energy transfer. This energy transfer occurs in the cavity of $\boldsymbol{\gamma}$ 10 cyclodextrin, and is efficient even with the most toxic PAHs and least fluorescent PCBs. The low limits of detection and potential for selective detection using array-based systems, combined with the straightforward experimental setup, make this new detection method particularly promising.

15 Polycyclic aromatic hydrocarbons (PAHs) ${ }^{1}$ and polychlorinated biphenyls (PCBs) are two of the ten most toxic classes of compounds according to the Center for Disease Control's ranking in $2011 ;^{2}$ as such, the development of sensitive and selective detection methods remains a top priority. PAHs are formed from 20 the incomplete combustion of petroleum, and their presence has been detected in human blood and breast milk, ${ }^{3}$ and in Gulf water seafood following the Gulf of Mexico oil spill. ${ }^{4}$ Some examples of PAHs and the FDA-recommended concentration limits of PAHs in seafood are shown in Figure $1 .^{5}$

25 PCBs were historically used as refrigerator coolants and in a variety of manufacturing products. ${ }^{6}$ Although the use of PCBs was banned in the United States in $1979,{ }^{7}$ their atmospheric stability means that PCBs still persist in the environment. ${ }^{8}$ Some examples of PCBs are shown in Figure 1; the FDA-recommended 30 concentration limits for PCBs in food ranges from 0.2-3.0 parts per million (ppm). ${ }^{9}$

Current methods for the detection of PAHs and PCBs generally rely on separation using chromatography, followed by detection via mass spectrometry (for $\mathrm{PAHs}^{10}$ and $\mathrm{PCBs}^{11}$ ) or

35 fluorescence spectroscopy (for PAHs). The development of new methods for the detection of these compounds remains a high priority, especially if such methods have improved sensitivity and/or selectivity.

We previously reported that energy transfer occurs between 40 anthracene and a squaraine fluorophore inside the cavity of $\gamma$ cyclodextrin, with up to $35 \%$ energy transfer observed from anthracene excitation compared to direct squaraine excitation. ${ }^{12}$ The energy transfer efficiency is defined as:

$$
\% \text { Efficiency }=\left(I_{\mathrm{DA}} / I_{\mathrm{D}}\right) * 100 \%
$$

$45(1)$

where $I_{\mathrm{DA}}$ is the integrated emission of the fluorophore from PAH excitation and $I_{\mathrm{D}}$ is the integrated fluorophore emission from direct excitation.

Although examples of energy transfer with covalently50 modified cyclodextrins have been reported, ${ }^{13}$ non-covalent energy transfer inside cyclodextrin cavities is much less developed, ${ }^{14}$ even though such energy transfer is substantially easier to tune and optimize. ${ }^{15}$

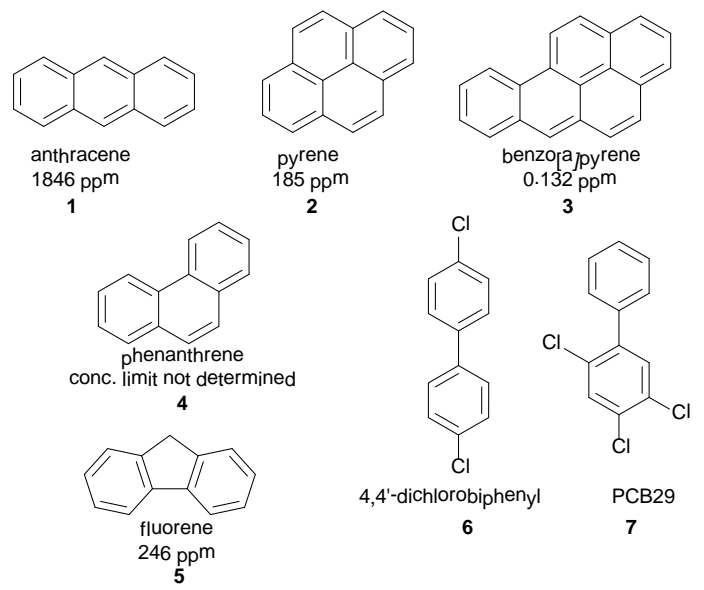

55 Figure 1: PAHs and PCBs used as energy donors, together with the FDArecommended concentration limits for PAHs in parts per million (ppm)

Reported herein is the development of a widely applicable non-covalent energy transfer system between PAH and PCB energy donors and fluorophore acceptors. These fluorophores 60 (Figure 2) were chosen because of their high quantum yields, ${ }^{16}$ and established use in a variety of sensing schemes. ${ }^{17}$ Compound $\mathbf{8}$ is commercially available, and compounds $\mathbf{9}$ and $\mathbf{1 0}$ were synthesized following known procedures. ${ }^{18}$

Energy transfer from the analytes to the fluorophores in the 65 presence of cyclodextrin was measured by mixing the analyte and fluorophore in a $\gamma$-cyclodextrin solution in phosphate-buffered saline (PBS) to generate a ternary complex. The complex was then excited near the absorbance maximum of the analyte and near the maximum of the fluorophore, and energy transfer 70 efficiencies were calculated.

Control experiments were also done in which the fluorophore was excited at the analyte's excitation wavelength in the absence of any analyte, to determine whether peaks previously identified as energy transfer peaks might be due to fluorophore emission 75 from excitation at a wavelength where it has non-zero absorbance. 


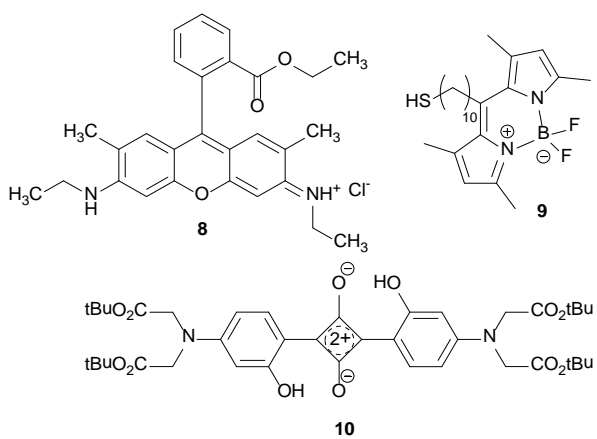

Figure 2: Structures of the fluorophores investigated

The results of these experiments were quantified as "fluorophore emission ratios," defined as the integrated fluorophore emission

5 in the absence of an analyte divided by the integrated fluorophore emission in the presence of the analyte (Table 1) (full results are in the Supporting Information).

Table 1 Fluorophore emission ratios at $10 \mathrm{mM} \gamma$-cyclodextrin

\begin{tabular}{lccc}
\hline & compound 8 & compound 9 & compound 10 \\
compound 1 & 0.99 & 0.98 & 1.09 \\
compound 2 & 0.20 & 0.27 & 0.73 \\
compound 3 & 0.05 & 0.09 & 0.91 \\
compound 4 & 1.48 & 0.95 & 0.34 \\
compound 5 & 1.73 & 0.60 & 0.97 \\
compound 6 & 1.99 & 1.63 & 0.99 \\
compound 7 & 1.89 & 1.78 & 0.87 \\
\hline
\end{tabular}

Defined as the ratio of fluorophore emission via indirect excitation in the 10 absence of the analyte to fluorophore emission via indirect excitation in the presence of the analyte. Any values between 0.95 and 1.05 indicate that any presumed energy transfer is merely a result of the fluorophore absorbing a non-trivial amount of energy via the "indirect" excitation pathway

15 These experiments revealed that some of the analytefluorophore pairs that have a significant fluorophore peak from analyte excitation actually have the same fluorophore peak in the absence of analyte (fluorophore emission ratio between 0.95 and 1.05). For several cases, however, the fluorophore emission ratios 20 were significantly higher than 1 (indicating that the analyte actually quenches fluorophore emission), and in other cases the ratio was significantly less than 1 (indicating that the desired energy transfer is observed). The maximum energy transfer efficiencies for all analyte-fluorophore combinations that 25 demonstrate energy transfer are shown in Table 2.

Table 2 Energy transfer efficiencies for each analyte-fluorophore combination

\begin{tabular}{lccc}
\hline & compound 8 & compound 9 & compound 10 \\
compound 1 & $c$ & $c$ & $35.2 \%$ \\
compound 2 & $6.0 \%$ & $a$ & $19.0 \%$ \\
compound 3 & $10.1 \%$ & $a$ & $27.4 \%$ \\
compound 4 & $b$ & $c$ & $b$ \\
compound 5 & $b$ & $18.7 \%$ & $c$ \\
compound 6 & $7.8 \%$ & $9.2 \%$ & $c$ \\
compound 7 & $b$ & $8.6 \%$ & $b$ \\
\hline
\end{tabular}

${ }^{a}$ Excessive overlap between the analyte and fluorophore prevented accurate integration

${ }_{30}{ }^{b}$ No fluorophore peak was observed from analyte excitation

$c$ Fluorophore emission ratios indicate no real energy transfer is occurring (emission ratios between 0.95 and 1.05).

Although anthracene (1) does not undergo significant energy transfer with fluorophores $\mathbf{8}$ and $\mathbf{9}$ (as measured by the
35 fluorophore emission ratios), the highly toxic PAHs 2 and $\mathbf{3}$ demonstrate significant energy transfer.

Benzo[a]pyrene $\mathbf{3}$ acted as an energy donor with fluorophores $\mathbf{8}$ and $\mathbf{9}$ (and to a limited extent with squaraine 10). The energy transfer peaks with compounds $\mathbf{8}$ and $\mathbf{1 0}$ are clearly visible at 558 $40 \mathrm{~nm}$ and $659 \mathrm{~nm}$, respectively (Figure 3). Control experiments also demonstrated the necessity of $\gamma$-cyclodextrin for energy transfer, as in the absence of cyclodextrin only 3\% energy transfer was observed for benzo[a]pyrene with compound 8 (compared to $10 \%$ in the presence of $10 \mathrm{mM} \gamma$-cyclodextrin). The detection of 45 benzo[ $[a]$ pyrene is particularly crucial, due to its low recommended concentration limit $(0.132 \mathrm{ppm})$ and high carcinogenicity.

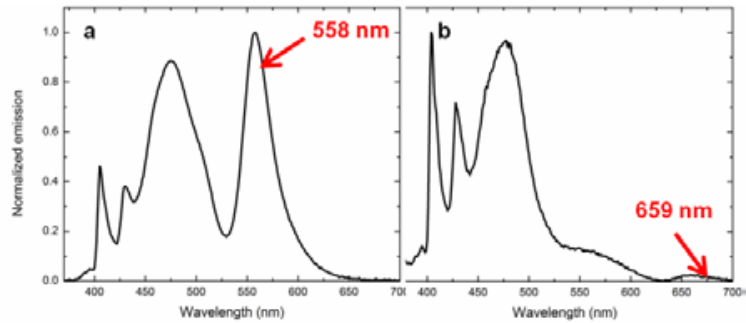

Figure 3: Energy transfer observed with compound $\mathbf{3}$ as an energy donor 50 with (a) compound $\mathbf{8}$ and (b) compound $\mathbf{1 0}$ as energy acceptors. The fluorophore emission maxima are shown in each case. (360 nm excitation; $10 \mathrm{mM} \nu$-cyclodextrin, $31.7 \mu \mathrm{M}$ compound 3 ; $8.35 \mu \mathrm{M}$ compound $\mathbf{8} ; 53.0$ $\mu \mathrm{M}$ compound 10)

The formation of ternary complexes with compound $\mathbf{2}$ as an 55 analyte can be measured by a decrease in the excimer emission in the presence of increasing amounts of fluorophore (Figure 4). Using pyrene $\mathbf{2}$ as an energy donor with compound $\mathbf{9}$ as an energy acceptor resulted in the sequential displacement of one molecule of pyrene from the $\mathrm{\gamma}$-cyclodextrin cavity and a concomitant 60 decrease in the pyrene excimer emission to $41 \%$ of its initial value (Figure 4). Both compounds $\mathbf{8}$ and $\mathbf{1 0}$ also acted as competent energy acceptors, with 6\% and 19\% energy transfer observed, respectively.

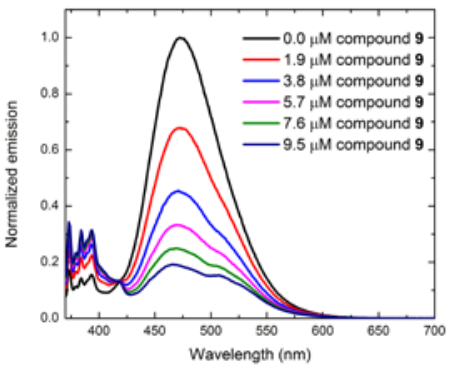

65 Figure 4: Decreased excimer emission of compound 2 in the presence of increasing amounts of fluorophore $\mathbf{9}$. (360 nm excitation; $10 \mathrm{mM} \mathrm{\gamma}$ cyclodextrin; $39.6 \mu \mathrm{M}$ compound 2)

Analytes 4-7 had significant interactions with fluorophores 8 and $\mathbf{9}$, as measured by their fluorophore emission ratios. For 70 fluorophore 8, introduction of analytes 4-7 led to a decrease in the fluorophore emission via low wavelength excitation compared to what is observed in the absence of the analyte (resulting in fluorophore emission ratios greater than 1). The nature of this interaction is not fully elucidated at this point, but nonetheless 75 has the potential to contribute to array-based detection of toxic 
analytes (see below).

In order for this energy transfer to be practical for the detection of toxic analytes, it needs to be both sensitive and selective. The sensitivity of this method was determined by quantifying the 5 limits of detection for all analyte-fluorophore combinations, ${ }^{19}$ and the results are shown in Table 3 . The limits of detection are defined as the amount of analyte necessary to observe a signal that is distinguishable from the baseline (see SI for details). ${ }^{20}$ The limits of detection for compounds $\mathbf{2}$ and $\mathbf{5}$ are below the FDA10 recommended concentration limits, thus providing a useful mechanism for the detection of these highly toxic analytes.

Table 3 Limits of detection for all analytes with fluorophores 8 -10 (all values given in parts per million (ppm))

\begin{tabular}{lccccccc}
\hline & $\mathbf{1}$ & $\mathbf{2}$ & $\mathbf{3}$ & $\mathbf{4}$ & $\mathbf{5}$ & $\mathbf{6}$ & $\mathbf{7}$ \\
$\mathbf{8}$ & $a$ & 5.9 & 104 & 83 & 32 & 12 & $a$ \\
$\mathbf{9}$ & $a$ & $a$ & 61 & 55 & 32 & $a$ & 9.8 \\
$\mathbf{1 0}$ & $a$ & $a$ & 31 & 43 & $b$ & $b$ & $b$
\end{tabular}

${ }^{a}$ Efforts to calculate limits of detection led to nonsensical values in these 15 cases. Current efforts are focused on solving this problem.

${ }^{b}$ Limits of detection were not calculated in these cases because no energy transfer was observed

Selectivity in the detection of toxic PAHs and PCBs can be accomplished using array-based detection. Such detection 20 systems have also been referred to as "chemical noses," and have been used successfully by a number of research groups. ${ }^{21}$ Arraybased detection generally requires exposure of an analyte to a receptor array. Statistical analyses of the resulting array of signals then lead to the selective detection of particular analytes.

25 Preliminary efforts towards developing an array-based detection system have yielded promising results. Using the three different fluorophores (compounds 8-10) in combination with 10 $\mathrm{mM}$ p-cyclodextrin, each analyte (PAH or PCB) displayed qualitatively different fluorescence patterns when excited at 365 $30 \mathrm{~nm}$ (Figure 5). Qualitatively different fluorescent responses were observed even in cases where the fluorophore emission ratios indicate some degree of fluorophore quenching from introduction of the analyte. The fact that each vertical column looks different means that each analyte has a different pattern of responses with 35 the fluorophores investigated. Efforts to translate this qualitative observation into a quantitative selective detection system are underway.

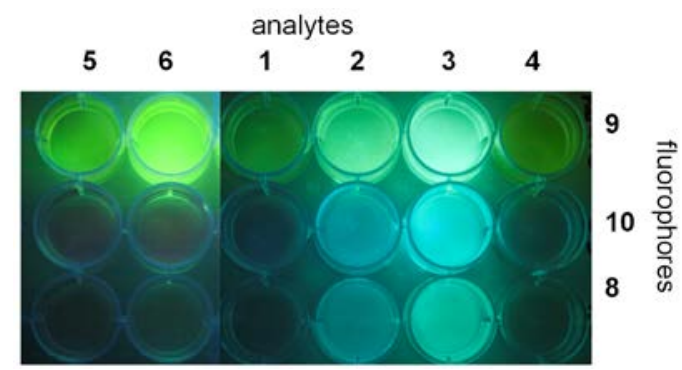

Figure 5: Photograph of a preliminary array using $10 \mathrm{mM} \gamma$-cyclodextrin 40 (excitation at $365 \mathrm{~nm}$ with a hand-held TLC lamp)

In summary, reported herein is the development of highly efficient non-covalent energy transfer in $\gamma$-cyclodextrin cavities between toxic energy donors and fluorescent energy acceptors. This energy transfer has a number of advantages compared to
45 previously-developed systems, including: (a) high sensitivity (as low as 5.9 ppm for compound 2); (b) ease of tunability; and (c) widespread applicability to two classes of highly toxic compounds. The development of a full array-based detection system, and a detailed investigation of the energy transfer 50 mechanism, are underway and the results will be reported in due course.

\section{Notes and references}

${ }^{a}$ Department of Chemistry, University of Rhode Island, 51 Lower College Road, Kingston, RI 02881, USA. Fax 401-874-5072; Tel: 401-874-4243;

55 E-mail: mlevine@chm.uri.edu

$\dagger$ This research was funded in part by a grant from the Gulf of Mexico Research Initiative (GOMRI).

† Electronic Supplementary Information (ESI) available: Syntheses of fluorophores 9 and 10; full tables of energy transfer efficiencies; compsite 60 figures of energy transfer in various cyclodextrin concentrations; zoomedin composite figures of all energy transfer experiments. See DOI: $10.1039 / \mathrm{b} 000000 \mathrm{x} /$

${ }^{1}$ Y. Guo, K. Wu, X. Huo and X. Xu, J. Env. Health, 2011, 73, 22.

${ }^{2}$ http://www.atsdr.cdc.gov/SPL/index.html

${ }^{3}$ I. Cok, B. Mazmanci, M. A. Mazmanci, C. Turgut, B. Henkelmann and K.-W. Schramm, Environ. Int., 2012, 40, 63.

${ }^{4}$ K. Xia, G. Hagood, C. Childers, J. Atkins, B. Rogers, L. Ware, K. Armbrust, J. Jewell, D. Diaz, N. Gatian and H. Folmer, Environ. Sci. Technol., 2012, 46, 5310.

${ }^{5}$ S. Gratz, A. Morhhaus, B. Gamble, J. Gracie, D. Jackson, J. Roetting, L. Ciolino, H. McCauley, G. Schneider, D. Crockett, W. Krol, T. Arsenault, J. White, M. Flottmeyer, Y. Johnson, D. Heitkemper and F. Fricke, Lab. Info. Bull., 2010, 4475, 1.

${ }^{6}$ V. D. Dang, D. M. Walters and C. M. Lee, Am. J. Environ. Sci. 2012, 8, 11.

${ }^{7}$ C. Aeppli, C. A. Carmichael, R. K. Nelson, K. L. Lemkau, W. M. Graham, M. C. Redmond, D. L. Valentine and C. M. Reddy, Environ. Sci. Technol., 2012, 46, 8799.

${ }^{8}$ N. B. Hopf, A. M. Ruder and P. Succop, Sci. Total Environ. 2009, 407, 6109.

9 "Polychlorinated Biphenyls (PCBs).” TEACH Chemical Summary; http://www.epa.gov/teach/.

${ }^{10}$ H. D. Duong, C. V. G. Reddy, J. I. Rhee and T. Vo-Dinh, Sensors Actuators B Chem., 2011, 157, 139.

${ }^{11}$ M. C. Bruzzoniti, R. Maina, V. Tumiatti, C. Sarzanini, L. Rivoira and R. M. De Carlo, J. Chromatography A., 2012, 1265, 31.

${ }^{12}$ T. Mako, P. Marks, N. Cook and M. Levine, Supramol. Chem., 2012, 24, 743.

${ }^{13}$ R. Menting, D. K. P. Ng, B. Roeder and E. A. Ermilov, Phys. Chem. Chem. Phys. 2012, 14, 14573.

${ }^{14}$ S. Hamai, J. Mater. Chem., 2005, 15, 2881.

${ }^{15}$ M. Levine, I. Song, T. L. Andrew, S. E. Kooi and T. M. Swager, J. Polym. Sci. A. Polym. Chem. 2010, 48, 3382.

${ }^{16}$ H. Zheng, X.-Q. Zhan, Q.-N. Bian and X.-J. Zhang, Chem. Commun., 2013, 49, 429.

${ }^{17}$ H. Kim, S. Wang, S.-H. Kim and Y.-A. Son, Molec. Cryst. Liq. Cryst., 2012, 566, 45.

${ }^{18}$ J. L. Shepherd, A. Kell, E. Chung, C. W. Sinclar, M. S. Workentin and D. Bizzotto, J. Am. Chem. Soc., 2004, 126, 8329; P. T. Snee, R. C. Somers, G. Nair, J. P. Zimmer, M. G. Bawendi and D. G. Nocera, J. Am. Chem. Soc., 2006, 128, 13320; Y. G. Isgor and E. U. Akkaya, Tetrahedron Lett., 1997, 38, 7417.

${ }^{19}$ B. Saute, R. Premasiri, L. Ziegler and R. Narayanan, Analyst, 2012, 137, 5082.

${ }^{20}$ J. Palarea-Albaladejo and J. A. Martin-Fernandez, Anal. Chim. Acta 2013, 764, 32.

${ }^{21}$ U. H. F. Bunz and V. M. Rotello, Angew. Chem. Int. Ed. 2010, 49, 3268; F. Wang and T. M. Swager, J. Am. Chem. Soc. 2011, 133, 11181. 